\title{
Investigation on the Sandwich System Hull Materials for Solar Powered Electrical Sport Boat
}

\author{
Sunaryo* and Aldy Syahrihaddin Hanifa \\ Naval Architecture and Marine Engineering Faculty of Engineering Universitas Indonesia, \\ Department of Mechanical Engineering, 16424 Depok, Indonesia
}

\begin{abstract}
Experiments and theoretical analyses of sandwich materials which are used in the design of a solar-powered boat are required to fully complete the analysis of the hull strength. Rule analysis of global hull girder loads or panel under global loads (laminate buckling, maximum stress in each layer, and combined stress) will be used to determine the hull strength of the boat. In this research, the mechanical properties of facing laminate and sandwich material of VARTM-Vacuum Infusion are investigated. Moreover, the analysis from the result of the experiment and the theoretical calculation will be used as a reference to perform the hull strength calculations. From the experiment, an average tensile modulus of 15.21 GPa is obtained with a standard deviation of $\pm 1 \mathrm{GPa}$ and the theoretical analyses calculation for the tensile modulus value is 54.9905 $\mathrm{GPa}$. Furthermore, an average flexural modulus value is $21261.8 \mathrm{~N} \mathrm{~mm}^{-2}$ with a standard deviation of $\pm 2301.17 \mathrm{~N} \mathrm{~mm}^{-2}$ and a theoretical analyses calculation for the flexural modulus value is $26833.5 \mathrm{~N} \mathrm{~mm}^{-2}$. In the end, the calculation from the experimental and theoretical analysis may be applicable to calculate the hull strength of the vessel. In conclusion, the calculation of the hull strength of the solar-powered boat using the Bureau Veritas (BV) classification rules has met the required standards.
\end{abstract}

Key words: Hull strength, sandwich laminate, solar energy on boat, Vacuum Assisted Resin Transfer Molding (VARTM).

\section{Introduction}

The work is a further development of the solar-powered boat created by the University of Indonesia team who participated in the International Solar-Boat Challenge in the Netherlands. The use of materials in constructing the boat is important in order to meet optimum weight and strength requirement. The aims of the study are: (i) to investigate the mechanical properties of proposed materials based on how they are manufactured, (ii) to ensure that the materials used in the solar-powered boat are accordant with the hull strength calculation, (iii) and to provide calculations that might be used for other purposes such as constructing recreational and sport boat made from the same method.

In previous research, the calculation of single-laminate composite materials which used a multiaxial type E-glass with vinyl ester resin and VARTM method is applied in the design of small-fast boat [1]. It shows that the application of VARTM-Vacuum Infusion

\footnotetext{
*Corresponding author: naryo@eng.ui.ac.id
} 
method can optimize the volume fraction of fiber and matrix content in the composite material. Another research shows that an analytical calculation of sandwich material using VARTM-vacuum infusion had been used to find the mechanical properties and economical value from the boat design by using the same method but different sandwich material composition. Another research shows that a sandwich material calculation with VARTMVacuum Infusion method was conducted to know more about the mechanical properties and economic calculation of sandwich material that applied in a boat design. The research shows that the core material (diviniycell) makes the sandwich material more rigid and thicker as well as enabling the reduction of the weight of the boat compared with the single skin laminate [2]. Furthermore, to investigate the calculation of sandwich material that might be used for other purposes such as constructing recreational and sport boat with thinner core material and higher mechanical properties material for skin laminate will be conducted in this research paper.

The hull strength calculation will be deducted on the Bureau Veritas Classification (BV) with the rule titled: Rules Hull in Composite Materials and Plywood, Material Approval, Design Principles, Construction and Survey (NR 546 DT R00 E). The calculation will use the analysis of a panel under global loads (laminate buckling, maximum stress in each layer, and combined stress) to determine the hull strength of the boat $[3,4]$. Furthermore, in this study, the mechanical properties (tensile and flexural) of facing laminate and sandwich material of VARTM (Vacuum Assisted Resin Transfer Molding)-Vacuum Infusion will be investigated with theoretical (micromechanical) [5] and experiment (ASTM C393 and ASTM D3039) analysis. These analyses will be used as a reference to perform the hull strength calculations. Moreover, in this work, panels that consist of two different materials (High Strength Carbon Fiber $240 \mathrm{~g} \mathrm{~m}^{-2}$ and Lantor Soric XF $5 \mathrm{~mm}$ ) infused with Ripoxy R-802 EX-1 (vinyl ester resin) are studied.

\section{Methodology}

\subsection{Hull}

The boat specifications are used to compile with the analysis of panel under global loads. The specifications of the boat are shown in Table 1 and Table 2.

Table 1. Boat specifications

\begin{tabular}{ll}
\hline Length overall & $5.8 \mathrm{~m}$ \\
Breadth & $1.8 \mathrm{~m}$ \\
Draft & $0.124 \mathrm{~m}$ \\
Height & $0.35 \mathrm{~m}$ \\
Block coeficient $(\mathrm{Cb})$ & 0.532 \\
Prismatic coeficient $(\mathrm{Cp})$ & 0.568 \\
Midship coeficient $(\mathrm{Cm})$ & 0.939 \\
Frame spacing (Longitudinal) & $0.5 \mathrm{~m}$ \\
Frame spacing (Transversal) & $0.26 \mathrm{~m}$ \\
\hline
\end{tabular}

Table 2. Hull Item List

\begin{tabular}{cccccc}
\hline Item & Quantity & kg & Item & Quantity & kg \\
\hline Hull weight & 1 & 86 & Motor controller & 1 & 5 \\
Solar panel 1 & 1 & 20 & Panel box & 1 & 10 \\
Solar panel 2 & 1 & 20 & Box fuse & 1 & 5 \\
Solar panel 3 & 1 & 20 & Battery box & 1 & 15 \\
Solar panel 4 & 1 & 20 & Cabin & 1 & 75 \\
Total weight (kg) & \multicolumn{2}{c}{ Electric motor } & 1 & 40 \\
\hline \multicolumn{5}{c}{ Total overall weight (kg) } \\
\hline \multicolumn{7}{c}{ Total weight (kg) } \\
\hline
\end{tabular}




\subsection{Materials}

In this work, the boat is made from the sandwich material that consists of Carbon Fiber HDC-524-3K with $240 \mathrm{~g} \mathrm{~m}^{-2}$ as facing laminate (layer 1, 2, 4, and 5) and uses Lantor Soric $\mathrm{XF}$ with a thickness of $5 \mathrm{~mm}$ (layer 3 ) as the core material. The sandwich material can be seen in Figure 1. The matrix that is used in this work is Ripoxy R-802 EX-1 (vinyl ester) with MEPOXE M (Methyl Ethyl Ketone Peroxide type M) catalyst and P-EX promoter [6]. The process to make the specimens uses the VARTM (Vacuum Assisted Resin Transfer Molding)-Vacuum infusion method.

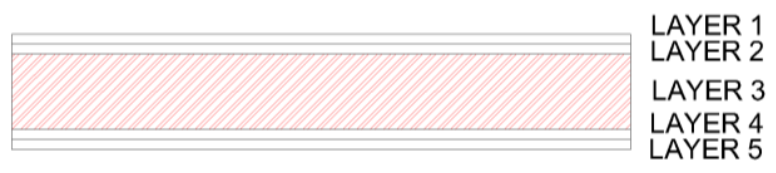

Fig. 1. Sandwich material.

\subsection{Hull strength analyses}

\subsubsection{Method}

The method that is used to find the value of panel under global loads is in accordance to BV rule. The mechanical properties (experiment and theoretical analyses calculation) of the materials should be calculated before compiling it with the analysis of panel under global loads. The experimental calculation will be conducted according to the standard under ASTM D3039 [7] for tensile modulus of facing laminate and ASTM C393 [8] for flexural modulus of the sandwich material. Micromechanical analysis will be used to calculate for the composite material.

\subsubsection{Global hull girder loads}

Analyses of panel under global loads will be used to determine the hull strength of the boat. The panels are a part of superstructures, hull shell or bulkhead. Moreover, all continuing members of the boat (longitudinal) will be calculated for the calculation of the hull strength. It can conclude that the boat would behave like a beam under this global deformation [9] because the ship has a slender body form. The calculation will be conducted with still water and wave loads condition. Moreover, there are three criteria for the hull strength analyses:

- Laminate buckling

- Maximum stress in each layer

- Combined stress in each layer

Laminate buckling must fulfill this condition:

$$
\begin{aligned}
& \sigma_{a} \leq \sigma_{c} / S F_{B} \\
& \tau_{\mathrm{a}} \leq \tau_{\mathrm{c}} / S F_{B}
\end{aligned}
$$

$\sigma_{a}, \tau_{\mathrm{a}}=$ compression stress and shear stress applied to the panel

$\sigma_{c}, \tau_{\mathrm{c}}=$ critical buckling stresses of the panel

$S F_{B}=$ minimum buckling rule safety coefficient

Maximum stress in each layer must fulfill this condition: 


$$
\begin{gathered}
\sigma_{i} \leq \sigma_{b r} / S F \\
\tau_{\mathrm{i}} \leq \tau_{\mathrm{br}} / S F
\end{gathered}
$$

$\sigma_{i}, \tau_{\mathrm{i}}=$ local stress in individual layers induced by in-plane global loads

$\sigma_{b r}, \tau_{\mathrm{br}}=$ theoretical breaking stress of layers

$S F=$ minimum buckling rule safety coefficient

Combined stress in each layer must fulfilled this condition:

$$
S F_{C S} \geq C_{V} \cdot C_{F} \cdot C_{C S} \cdot C_{I}
$$

$C_{v}=$ rule partial safety coefficient taking into account the ageing effect on the laminates

$C_{F}=$ rule partial safety coefficient taking into account the fabrication process

$C_{C S}=$ rule partial safety coefficient for combined stresses in the individual layers of the laminates

$C_{I}=$ rule partial safety coefficient taking into account the type of the loads

$$
\begin{gathered}
S F_{C S}=\left\{-b \pm\left[b^{2}+4 a\right]^{0.5}\right\} / 2 a \\
a=\left\{\sigma_{1}^{2} /\left[\left|\sigma_{b r c l} \cdot \sigma_{b r t 1}\right|\right]\right\}+\left\{\sigma_{2}^{2} /\left[\left|\sigma_{b r c 2} \cdot \sigma_{b r c 2}\right|\right]\right\}-\left\{\sigma_{1} \cdot \sigma_{2} /\left[\left|\sigma_{b r c 1} \cdot \sigma_{b r t 1}\right|\right]\right\}+\left\{\tau_{12}{ }^{2} / \tau_{b r 12}{ }^{2}\right\} \\
b=\left\{\left[\sigma_{1}\left(\left|\sigma_{b r c l}\right|-\left|\sigma_{b r t 1}\right|\right)\right] /\left[\left|\sigma_{b r c 1} \cdot \sigma_{b r t 1}\right|\right]\right\}-\left\{\left[\sigma_{2}\left(\left|\sigma_{b r c 2}\right|-\left|\sigma_{b r t 2}\right|\right)\right] /\left[\left|\sigma_{b r c 2} \cdot \sigma_{b r t 2}\right|\right]\right\}
\end{gathered}
$$

$\sigma_{i}, \tau_{12}=$ actual stresses, in the considered ply axis induce by the loading case

$\sigma_{b r i}, \tau_{\text {br12 }}=$ ply theoretical breaking stresses in the local ply axis

\subsubsection{Theoretical breaking stress layer 1,2, 4, and 5}

The breaking stress analytical calculation for layers 1, 2, 4, and 5 with Carbon Fiber HDC-524-3K $240 \mathrm{~g} \mathrm{~m}^{-2}$ material uses the theoretical calculation obtained from the BV classification rules. The Equations for theoretical breaking stress are shown below:

$$
\begin{aligned}
& \sigma_{b r t l}=\varepsilon_{b r t l} . E_{l} . \text { Coef }_{\text {res }} \\
& \sigma_{b r c l}=\varepsilon_{b r c l} . E_{l} . \text { Coef } f_{\text {res }} \\
& \sigma_{b r t 2}=\varepsilon_{b r t 2} . E_{2} . \text { Coef } f_{\text {res }} \\
& \sigma_{b r c 2}=\varepsilon_{b r c 2} . E_{2} \text {. Coef res } \\
& \tau_{\text {brt12 }}=\gamma_{\text {brl2 }} . G_{12} \text {. Coef } f_{\text {res }} \\
& \tau_{\text {brIL1 }}=\gamma_{\text {bril23 }} \cdot G_{23} \text {. Coef } f_{\text {res }} \\
& \tau_{\text {brIL2 }}=\gamma_{\text {brill3 }} . G_{13} . \text { Coef }_{\text {res }}
\end{aligned}
$$

$\sigma_{b r t 1,2}=$ tensile break stress $1 \& 2$ direction

$\sigma_{b r c 1,2}=$ compression break stress $1 \& 2$ direction

$\tau_{\text {br } 12}=$ shear break stress 12 direction

$\tau_{\text {brIL } 1,2}=$ inter laminar shear break stress $1 \& 2$ direction

$\mathrm{E}_{\mathrm{i}}=$ young modulus

$\mathrm{G}_{\mathrm{i}}=$ shear modulus

Table 3 shows break strain values for high strength carbon fiber type. 
Table 3. Break strain

\begin{tabular}{llll}
\hline Carbon & High strength & Carbon & High strength \\
\hline $\boldsymbol{\varepsilon}_{\text {brt1 }}$ & $1 \%$ & $\boldsymbol{\varepsilon}_{\text {brc2 }}$ & $0.85 \%$ \\
$\boldsymbol{\varepsilon}_{\text {brt2 }}$ & $1 \%$ & $\boldsymbol{\gamma}_{\text {br12 }}$ & $1.55 \%$ \\
$\boldsymbol{\varepsilon}_{\text {brc1 }}$ & $0.85 \%$ & $\boldsymbol{\gamma}_{\text {br13 }}, \boldsymbol{\gamma}_{\text {brIL2 }}$ & $1.55 \%$ \\
\hline
\end{tabular}

\subsubsection{Theoretical breaking stress layer 3}

The theoretical breaking stress for layer 3 is calculated with micromechanical analysis as shown in Equation (16).

$$
E_{l}=E_{f} V_{f}+E_{m} V_{m}
$$

$\mathrm{E}_{1}=$ Young modulus for laminate

$\mathrm{V}_{\mathrm{f} ; \mathrm{m}}=$ Volume faction fiber (lantor soric); matrix

$\mathrm{E}_{\mathrm{f} ; \mathrm{m}}=$ Young modulus from fiber (lantor soric); matrix

The Young modulus value from lantor soric XF can be neglected, and the mechanical properties of the core material infused with resin are only affected by the volume fraction of the resin type (matrix) that is used in the VARTM-vacuum infusion process [10].

\subsection{Experiment analysis for tensile modulus and flexural modulus of the materials}

The test to find the value of tensile modulus for facing laminate uses the ASTM D3039 standard. The size of the specimens has a total length of $250 \mathrm{~mm}$, width of $25 \mathrm{~mm}$, and gauge length of $150 \mathrm{~mm}$ as seen in Figure 2.

Three-point bending test specimens will be prepared in accordance with ASTM C393 to get the flexural modulus value from the sandwich material. The specimens will have a total length of $200 \mathrm{~mm}$, width of $75 \mathrm{~mm}$, and support span of $150 \mathrm{~mm}$, and the load span will be in the middle of the specimens as seen in Figure 2.

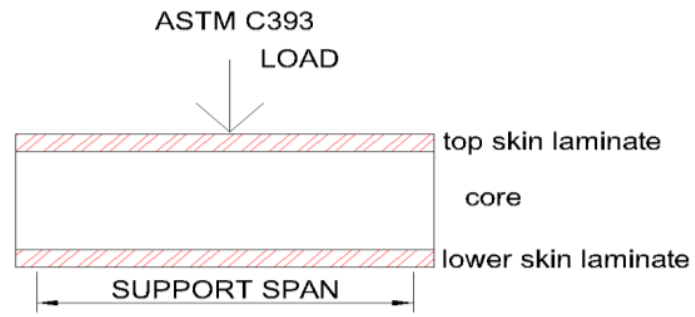

ASTM D3039

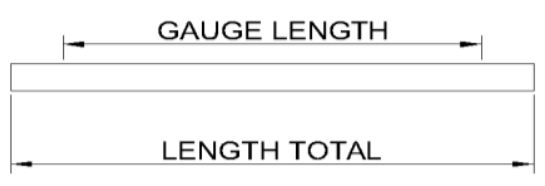

Fig. 2. ASTM C393 and ASTM D3039 


\section{Results and discussion}

\subsection{Experiment and analyses/theoretical calculation of sandwich material}

\subsubsection{Tensile experiment and analyses/theoretical calculation}

This experiment uses five specimens of facing laminate that consists of Carbon Fiber HDC524-3K with $240 \mathrm{gr} \mathrm{m}^{-2}$. The stress-strain graph is obtained during the experiment as seen in Figure 3. The test was conducted at STP BPPT Serpong, with a temperature of $21.7^{\circ} \mathrm{C}$ and constant speed of $2 \mathrm{~mm} \mathrm{~min}^{-1}$. As can be seen from the graph, a linear line is formed between stress vs strain in all the five specimens. From the experiment, an average tensile modulus of $15.21 \mathrm{GPa}$ with a standard deviation $\pm 1 \mathrm{GPa}$ is obtained. Furthermore, with the analysis/theoretical calculation, the value of an average tensile modulus is $54.9905 \mathrm{GPa}$.

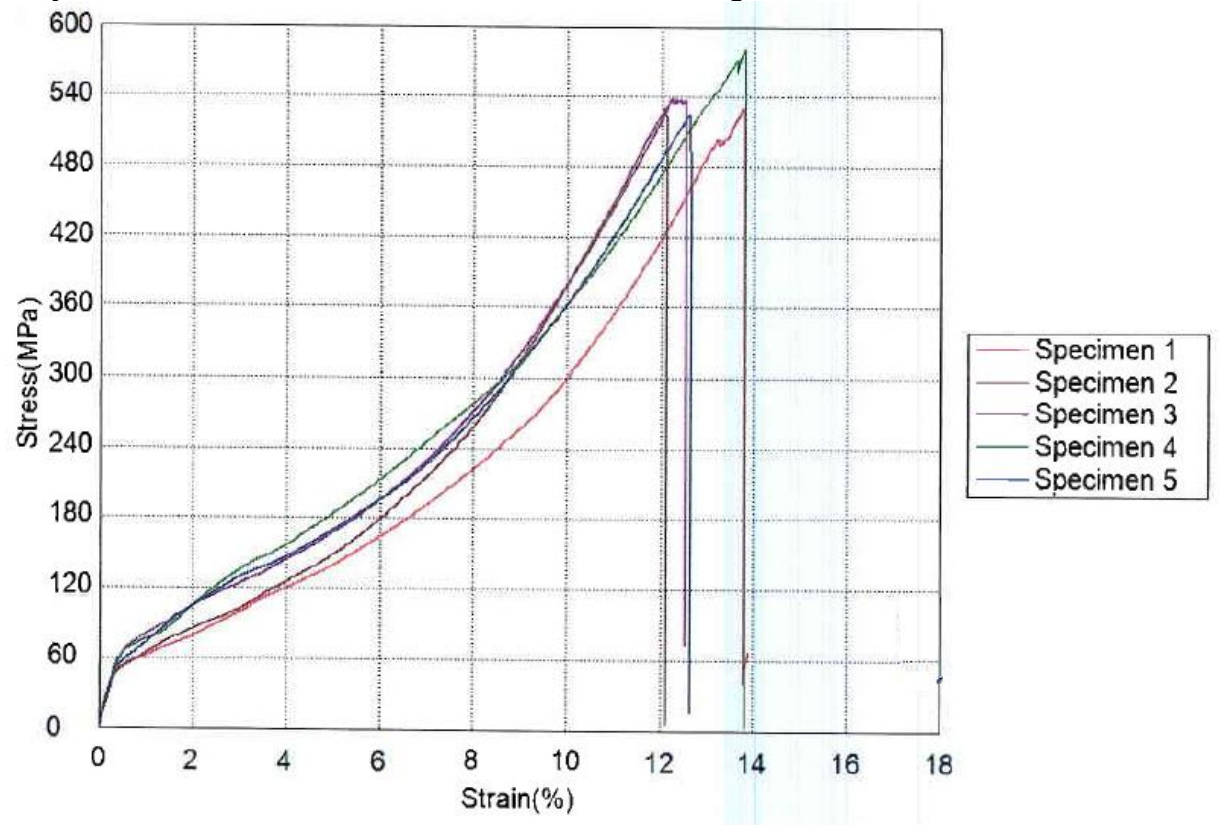

Fig. 3. Stress VS Strain ASTM D3039 for Facing Laminate

\subsubsection{Flexural experiment and analyses/theoretical calculation}

This experiment uses five specimens of sandwich material. The graph between stress vs. strain is obtained during the experiment (Figure 4.). The test was conducted at STP BPPT Serpong, with a temperature of $23.1{ }^{\circ} \mathrm{C}$ and a constant speed of $6 \mathrm{~mm} \mathrm{~min}^{-1}$. It can be seen from the graph that a linear line is formed between stress vs. strain in all the five specimens before the failure occur. From the experiment, an average flexural modulus of $21261.8 \mathrm{~N}$ $\mathrm{mm}^{-2}(21.2618 \mathrm{GPa})$ with a standard deviation of $\pm 2301.17 \mathrm{~N} \mathrm{~mm}^{-2}( \pm 2.30117 \mathrm{GPa})$ is obtained. Moreover, an analytical/theoretical calculation for the flexural modulus value is $26833.5 \mathrm{~N} \mathrm{~mm}^{-2}(26.8335 \mathrm{GPa})$. 


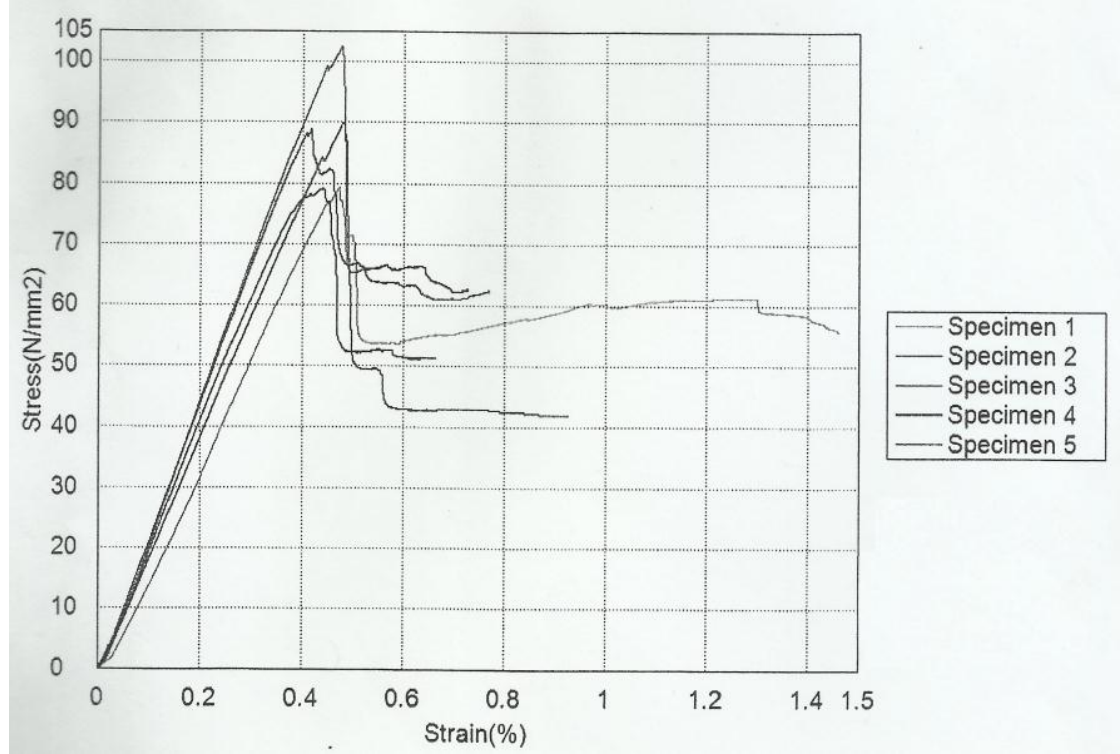

Fig. 4. Stress VS Strain ASTM C393 for Sandwich Material

\subsection{Hull Strength}

Hull strength calculation is conducted by the panel under global loads that is based on the regulation issued by the BV, titled: "Rules Hull in Composite Materials and Plywood, Material Approval, Design Principles, Construction and Survey (NR 546 DT R00 E)". The values of the hull strength of the boat are as follows:

- Laminate buckling (Table 4.) where the Equation (1) and Equation (2) are used to know the values.

Table 4. Laminate buckling

\begin{tabular}{llll}
\hline Condition & Hogging & Sagging & Pass/not pass \\
\hline$\sigma_{a} \leq \sigma_{c} / S F_{B}\left(\mathrm{~N} \mathrm{~mm}^{-2}\right)$ & $0.86 \leq 460.975$ & $0.25 \leq 460.975$ & pass \\
& & & \\
$\tau_{a} \leq \tau_{c} / S F_{B}\left(\mathrm{~N} \mathrm{~mm}^{-2}\right)$ & $0.062 \leq 129.139$ & $0.0135 \leq 129.139$ & pass \\
\hline
\end{tabular}

In this criteria, global hull girder loads assumption is used where this value is assumed that all parts of the vessel's body are considered as a beam. The force and moment caused by the local load on the ship react to all parts of the ship $[14,15]$. The hull strength from Table 4 is divided into two wave load conditions: hogging and sagging. The hull sandwich material must satisfy the condition according to the BV rules in any condition. These conditions are the critical buckling of the hull sandwich material which must be higher than the tensile or compression stress that occurs due to the interaction between boat load and wave load (hogging or sagging).

- Maximum stress in each layer (Table 5, Table 6, and Table 7) and maximum stress between the layers (Table 8) where the Equations (3), (4), (9), (10), (11), (12), (13), (14), and (15) are used to find the values. 
Table 5. Maximum stress in each layer (bottom area)

\begin{tabular}{|c|c|c|c|}
\hline \multicolumn{4}{|c|}{ Bottom } \\
\hline \multicolumn{2}{|c|}{ Layer 1} & \multicolumn{2}{|c|}{$\boldsymbol{\sigma} \leq \boldsymbol{\sigma}$ brk $/ \mathrm{Sf}$} \\
\hline $\boldsymbol{\sigma} 1(\mathrm{MPa})$ & 0.183 & 122.02 & pass \\
\hline $\mathrm{MPa})$ & 0.012 & 122.02 & pass \\
\hline \multicolumn{2}{|c|}{ Layer 2} & \multicolumn{2}{|c|}{$\boldsymbol{\sigma} \leq \boldsymbol{\sigma} \mathrm{brk} / \mathrm{Sf}$} \\
\hline $\boldsymbol{\sigma} 1(\mathrm{MPa})$ & 0.183 & 122.02 & pass \\
\hline $\boldsymbol{\sigma} 2(\mathrm{MPa})$ & 0.612 & 122.02 & pass \\
\hline \multicolumn{2}{|c|}{ Layer 3} & \multicolumn{2}{|c|}{$\boldsymbol{\sigma} \leq \boldsymbol{\sigma}$ brk $/ \mathrm{Sf}$} \\
\hline $\boldsymbol{\sigma} 1(\mathrm{MPa})$ & 0.00697 & 15 & pass \\
\hline $\boldsymbol{\sigma} 2(\mathrm{MPa})$ & 0.0175 & 15 & pass \\
\hline \multicolumn{2}{|c|}{ Layer 4} & \multicolumn{2}{|c|}{$\boldsymbol{\sigma} \leq \boldsymbol{\sigma} \mathrm{brk} / \mathrm{Sf}$} \\
\hline $\boldsymbol{\sigma} 1(\mathrm{MPa})$ & 0.183 & 122.02 & pass \\
\hline $\boldsymbol{\sigma} 2(\mathrm{MPa})$ & 0.612 & 122.02 & pass \\
\hline \multicolumn{2}{|c|}{ Layer 5} & \multicolumn{2}{|c|}{$\boldsymbol{\sigma} \leq \boldsymbol{\sigma}$ brk $/ \mathrm{Sf}$} \\
\hline $\boldsymbol{\sigma} 1(\mathrm{MPa})$ & 0.183 & 122.02 & pass \\
\hline $\boldsymbol{\sigma} 2(\mathrm{MPa})$ & 0.612 & 122.02 & pass \\
\hline
\end{tabular}

In Table 5, for each layer on bottom side of the boat, the local stress in individual layers induced by in-plane global loads according to the BV was calculated. The value of the local stress for each layer must be smaller than the maximum theoretical breaking stress for each layer in sandwich material composition. In Table 6 and Table 7, the same logic applies as in Table 5, but the local stress that is induced by in-plane global loads is on a different location (side and deck of the boat).

Table 6. Maximum stress in each layer (side area)

\begin{tabular}{|c|c|c|c|c|c|c|c|}
\hline \multicolumn{4}{|c|}{ Side } & \multicolumn{4}{|c|}{ Side } \\
\hline \multicolumn{2}{|c|}{ Layer 1} & \multicolumn{2}{|c|}{$\boldsymbol{\sigma} \leq \boldsymbol{\sigma} \mathrm{brk} / \mathrm{Sf}$} & \multicolumn{2}{|c|}{ Layer 4} & \multicolumn{2}{|c|}{$\boldsymbol{\sigma} \leq \boldsymbol{\sigma} \mathrm{brk} / \mathrm{Sf}$} \\
\hline $\boldsymbol{\sigma} 1(\mathrm{MPa})$ & $5.62465 \mathrm{E}-06$ & 122.02 & pass & $\boldsymbol{\sigma} 1(\mathrm{MPa})$ & -5.055 97E-06 & -103.7172 & pass \\
\hline $\boldsymbol{\sigma} 2(\mathrm{MPa})$ & $5.4304 \mathrm{E}-06$ & 122.02 & pass & $\boldsymbol{\sigma} 2(\mathrm{MPa})$ & $-4.88136 \mathrm{E}-06$ & -103.7172 & pass \\
\hline \multicolumn{2}{|c|}{ Layer 2} & \multicolumn{2}{|c|}{$\boldsymbol{\sigma} \leq \boldsymbol{\sigma} \mathrm{brk} / \mathrm{Sf}$} & \multicolumn{2}{|c|}{ Layer 5} & \multicolumn{2}{|c|}{$\boldsymbol{\sigma} \leq \boldsymbol{\sigma}$ brk $/ \mathrm{Sf}$} \\
\hline $\boldsymbol{\sigma} 1(\mathrm{MPa})$ & 5.055 97E-06 & 122.02 & pass & $\boldsymbol{\sigma} 1(\mathrm{MPa})$ & $-5.62465 \mathrm{E}-06$ & -103.7172 & pass \\
\hline $\boldsymbol{\sigma} 2(\mathrm{MPa})$ & $4.88136 \mathrm{E}-06$ & 122.02 & pass & $\boldsymbol{\sigma} 2(\mathrm{MPa})$ & $-5.4304 \mathrm{E}-06$ & -103.7172 & pass \\
\hline \multicolumn{2}{|c|}{ Layer 3} & \multicolumn{2}{|c|}{$\boldsymbol{\sigma} \leq \boldsymbol{\sigma}$ brk $/ \mathrm{Sf}$} & & & & \\
\hline $\boldsymbol{\sigma} 1(\mathrm{MPa})$ & $1.45971 \mathrm{E}-23$ & 15 & pass & & & & \\
\hline $\boldsymbol{\sigma} 2(\mathrm{MPa})$ & $1.41848 \mathrm{E}-23$ & 15 & pass & & & & \\
\hline
\end{tabular}


Table 6. Maximum stress in each layer (deck area)

\begin{tabular}{|c|c|c|c|}
\hline \multicolumn{4}{|c|}{ Deck } \\
\hline \multicolumn{2}{|c|}{ Layer 1} & \multicolumn{2}{|c|}{$\boldsymbol{\sigma} \leq \boldsymbol{\sigma} \mathrm{brk} / \mathrm{Sf}$} \\
\hline $\boldsymbol{\sigma} 1(\mathrm{MPa})$ & 0.1035 & 122.02 & pass \\
\hline $\boldsymbol{\sigma} 2(\mathrm{MPa})$ & 0.332 & 122.02 & pass \\
\hline \multicolumn{2}{|c|}{ Layer 2} & \multicolumn{2}{|c|}{$\boldsymbol{\sigma} \leq \boldsymbol{\sigma b r k} / \mathrm{Sf}$} \\
\hline $\boldsymbol{\sigma} 1(\mathrm{MPa})$ & 0.103 & 122.02 & pass \\
\hline $\boldsymbol{\sigma} 2(\mathrm{MPa})$ & 0.3312 & 122.02 & pass \\
\hline \multicolumn{2}{|c|}{ Layer 3} & \multicolumn{2}{|c|}{$\boldsymbol{\sigma} \leq \boldsymbol{\sigma} \mathrm{brk} / \mathrm{Sf}$} \\
\hline $\boldsymbol{\sigma} 1(\mathrm{MPa})$ & 0.003715 & 15 & pass \\
\hline $\boldsymbol{\sigma} 2(\mathrm{MPa})$ & 0.00933 & 15 & pass \\
\hline \multicolumn{2}{|c|}{ Layer 4} & \multicolumn{2}{|c|}{$\boldsymbol{\sigma} \leq \boldsymbol{\sigma}$ brk $/ \mathrm{Sf}$} \\
\hline $\boldsymbol{\sigma} 1(\mathrm{MPa})$ & 0.093 & 122.02 & pass \\
\hline $\boldsymbol{\sigma} 2(\mathrm{MPa})$ & 0.321 & 122.02 & pass \\
\hline \multicolumn{2}{|c|}{ Layer 5} & \multicolumn{2}{|c|}{$\boldsymbol{\sigma} \leq \boldsymbol{\sigma b r k} / \mathrm{Sf}$} \\
\hline $\boldsymbol{\sigma} 1(\mathrm{MPa})$ & 0.0922 & 122.02 & pass \\
\hline $\boldsymbol{\sigma} 2(\mathrm{MPa})$ & 0.321 & 122.02 & pass \\
\hline
\end{tabular}

Table 7. Maximum stress between layers

\begin{tabular}{|c|c|c|c|}
\hline \multicolumn{4}{|c|}{ Between layer 1 and layer 2} \\
\hline \multicolumn{2}{|c|}{$\begin{array}{l}\text { Maximum value } \\
\text { rom bottom, } \\
\text { side, and deck } \\
(\mathrm{MPa})\end{array}$} & $\begin{array}{c}\tau \mathrm{brk} / \mathrm{SF} \\
(\mathrm{MPa})\end{array}$ & $\begin{array}{c}\tau \mathrm{i} \leq \\
\tau \mathrm{brk} / \mathrm{SF}\end{array}$ \\
\hline$\tau y z$ & 0.009 & 12.58 & Pass \\
\hline$\tau \mathrm{xZ}$ & 0.064 & 12.58 & Pass \\
\hline \multicolumn{4}{|c|}{ Between layer 3 and layer 4} \\
\hline $\begin{array}{l}\text { Maxir } \\
\text { from } \\
\text { side, } \\
(\mathrm{MPa})\end{array}$ & $\begin{array}{l}\text { value } \\
\text { bottom, } \\
\text { and deck }\end{array}$ & $\begin{array}{c}\tau \text { brk/SF } \\
(\mathrm{MPa})\end{array}$ & $\begin{array}{c}\boldsymbol{\tau} \mathrm{i} \leq \\
\boldsymbol{\tau} \mathrm{brk} / \mathrm{SF}\end{array}$ \\
\hline$\tau \mathrm{tyz}$ & -0.014 & -1.273 & pass \\
\hline$\tau \mathrm{xZ}$ & -0.0999 & -1.273 & pass \\
\hline
\end{tabular}

\begin{tabular}{|c|c|c|c|}
\hline \multicolumn{4}{|c|}{ Between layer 2 and layer 3 } \\
\hline $\begin{array}{c}\text { Maximum value } \\
\text { from bottom, side, } \\
\text { and deck (MPa) }\end{array}$ & $\begin{array}{c}\boldsymbol{\tau} \text { brk/SF } \\
(\mathrm{MPa})\end{array}$ & $\begin{array}{c}\boldsymbol{\tau} \text { i } \leq \\
\boldsymbol{\tau} \text { brk/SF }\end{array}$ \\
\hline $\boldsymbol{\tau}$ yz & 0.01707 & 1.273 & pass \\
\hline $\boldsymbol{\tau}$ xz & 0.1241 & 1.273 & pass \\
\hline \multicolumn{4}{|c|}{ Between layer 4 and layer 5 } \\
\hline $\begin{array}{c}\text { Maximum value } \\
\text { from bottom, } \\
\text { side, and deck } \\
\text { (MPa) }\end{array}$ & $\begin{array}{c}\boldsymbol{\tau} \text { brk/SF } \\
(\mathrm{MPa})\end{array}$ & $\begin{array}{c}\boldsymbol{\tau} \text { i } \leq \\
\boldsymbol{\tau} \text { brk/SF }\end{array}$ \\
\hline $\boldsymbol{\tau}$ yz & -0.0222 & -12.58 & pass \\
\hline $\boldsymbol{\tau}$ xz & -0.1577 & -12.58 & pass \\
\hline
\end{tabular}

Table 7 shows the maximum value of interlaminar shear stress between the layers of sandwich material in different locations. The minus sign only shows the direction of the material and not the value. Interlaminar shear stress, induced by the global loads for each layer, must be smaller than the interlaminar shear break stress according to each layer of material.

- Combined stress in each layer (Table 8 and Table 9) where the Equations (5), (6), (7) and (8) are used to find the values. 
Table 8. Combined stress for layer 1,2, 4, and 5

\begin{tabular}{|l|l|l|l|}
\hline Position & Maximum (SFcs1 or SFcs2) & $C_{V} \cdot C_{F} \cdot C_{C S} \cdot C_{I}$ & $S F_{C S} \geq C_{V} \cdot C_{F} \cdot C_{C S} \cdot C_{I}$ \\
\hline Bottom & 844.55 & 2.808 & pass \\
\hline Side & 88599160.55 & 2.808 & pass \\
\hline Deck & 1563.366 & 2.808 & pass \\
\hline
\end{tabular}

Table 9. Combined stress for layer 3

\begin{tabular}{|l|l|l|l|}
\hline Position & Maximum (SFcs1 or SFcs2) & $C_{V} \cdot C_{F} \cdot C_{C S} \cdot C_{I}$ & $S F_{C S} \geq C_{V} \cdot C_{F} \cdot C_{C S} \cdot C_{I}$ \\
\hline Bottom & 2162.445 & 2.808 & pass \\
\hline Side & $2.2924 \mathrm{E}+24$ & 2.808 & pass \\
\hline Deck & 4054.585 & 2.808 & pass \\
\hline
\end{tabular}

The combined stress for each layer is calculated according to the BV regulation rules. The coefficient value is different when using different method and material for the boat strength calculation. The maximum value of SFcs1 and SFcs2 is according to Equation (6), (7), and (8). The actual stresses in the considered ply axis induced by the loading case and theoretical breaking stresses in the local ply axis is included as can be seen in Equation (7) and (8).

\section{Conclusions}

The boat that consists of sandwich material in this work with an approach of hull strength calculation from the BV could optimize the use of materials in accordance with the boatload design. Moreover, the mechanical properties of the materials have different values between the experiments and the analytical/theoretical calculation. This might happened because of three main reasons. First, resin vinyl ester Ripoxy R-802 EX-1 that is used in this work is more suitable with glass rather than carbon. Second, there might be unsuitable room temperature when the curing process started. Last, the catalyst from MEPOXE M (Methyl Ethyl Ketone Peroxide type M) is less compatible with resin vinyl ester Ripoxy R802 EX-1. Therefore it is recommended to use CHP (Chumene Hydroperoxide) as a catalyst for the vacuum infusion process.

Furthermore, there is a similarity between the flexural modulus analytical/theoretical calculation and flexural modulus experiment result. Hence, the theoretical analysis calculation can be used to calculate the hull strength in accordance with the BV rules. Moreover, in the final result, the hull strength analysis of laminate buckling, maximum stress in each layer, and combined stress passed is in accordance to the boatload design. In the end, this work might be used to calculate another vessel such as recreational and sports boat that are constructed using the same method or materials.

\section{References}

1. G.P. Liston, Sunaryo, G. Prayogo. Analisa sifat mekanik komposit vinyl ester berpenguat serat e-glass tipe multiaxial dengan metode VARTM untuk aplikasi pada lambung kapal cepat. [Mechanical analysis of multiaxial type e-glass fiber composites with vinyl ester matrix with VARTM method for applications on fast boat hull]. Proceeding Seminar Nasional Tahunan Teknik Mesin XIV (SNTTM XIV), (Banjarmasin, Indonesia, 2015), Material 08. [in Bahasa Indonesia]. https://www.researchgate.net/publication/309373826 
2. R.L. Muchtiwibowo, P. Manik, S. Jokosisworo. Jurnal Teknik Perkapalan, 4,1: 314 322(2016). [in Bahasa Indonesia].

https://ejournal3.undip.ac.id/index.php/naval/article/view/13801

3. Marine Division Bureau Veritas. Hull in composite materials and plywood, material approval, design principles. [Online] from https://www.veristar.com/portal/veristarinfo/files/sites/veristarinfo/web\%20contents/bvcontent/generalinfo/giRulesRegulations/bvRules/rulenotes/documents/546-NR 201702.pdf (2012) [Acessed on 17 April 2016].

4. Marine Division Bureau Veritas. Rules for the classification and the certification of yachts. [Online] from https://marine-offshore.bureauveritas.com/bv-rules (2012). [Acessed on 17 April 2016].

5. A.K Kaw. Mechanics of composite materials. US: CRC Press (2006). p. 203-2096 https://www.crcpress.com/Mechanics-of-Composite-

Materials/Kaw/p/book/9780849313431

6. Justus Sakti Raya. Technical information of corrosion guide and others. Jakarta: PT. Justus Sakti Raya (2009). [Review Document].

7. ASTM. ASTM D3039 standard test method for tensile properties of polymer matrix composite materials. West Conshohocken, PA: ASTM (2017). p. 1-13 https://www.astm.org/Standards/D3039

8. ASTM. ASTM C393 standard test method for core shear properties of sandwich constructions by beam flexure. West Conshohocken, PA: ASTM (2016). p. 1-8. https://www.astm.org/Standards/C393.htm

9. M. Mano. Structural design loads. In: Design of ship hull structures. Y. Okumoto, Y. Takeda, M. Mano, T. Okada (Eds). Verlag Berlin Heidelberg: Springer (2009). p. 17. https://www.springer.com/gp/book/9783540884446

10. B.V Lantor. Aplication manual. Veenendaal: Lantor B.V (2012). p. 26-30. https://wendashop.mycashflow.fi/files/Tuotetietokortit/Lantor\%20Application\%20Man ual.pdf 